\title{
THE MAJOR SUDDEN STRATOSPHERIC WARMING IMPACT ON MID- LATITUDE SURFACE WEATHER
}

\author{
Yuke Wang $^{1 *}$, Oleksandr Evtushevsky ${ }^{2}$, Gennadi Milinevsky ${ }^{1,2,3}$, Valery Shulga ${ }^{1,4}$, Yuliia \\ Yukhymchuk $^{3}$, Wei Han ${ }^{1}$, Dmitri Shulga ${ }^{4}$, Asen Grytsai ${ }^{2}$ \\ ${ }^{I}$ College of Physics, International Center of Future Science, Jilin University, Changchun 130012, China \\ ${ }^{2}$ Taras Shevchenko National University of Kyiv, Kyiv 01601, Ukraine \\ ${ }^{3}$ Main Astronomical Observatory of Ukraine, Kyiv 03143, Ukraine \\ ${ }^{4}$ Institute of Radio Astronomy, National Academy of Sciences of Ukraine, Kharkiv 61002, Ukraine
}

*Email:wangyk16@mails.jlu.edu.cn

\begin{abstract}
The possible relation of a major sudden stratospheric warming (SSW) with the midlatitude surface weather conditions was investigated using data from the ERA-Interim and NCEP-NCAR reanalyzes. An important feature of the SSW event is the impact on lower altitudes, when temperature and wind anomalies descend downward into the high- and mid-latitude troposphere during the weeks or even month and influence the surface weather $[1,2]$. Owing to known SSW impacts on the surface weather [2], we consider the possible relation of the SSW event in winter 2018 to cold weather anomaly in the Northern Ukraine and North-East China in February 2018.
\end{abstract}

\section{INTRODUCTION}

The event of major sudden stratospheric warming (SSW) which happened roughly each two years in the North Polar region is produced by strong planetary wave activity. The major SSW is accompanied by dramatic increase of the stratosphere temperature up to $50 \mathrm{~K}$ and zonal wind reverse from climatologically westerlies to easterlies during several days $[3,4,5]$. The SSW event can impact on lower altitudes and midlatitude troposphere changing the surface weather significantly. The SSW event in February 2018 shows enhanced warming in the stratosphere and cooling in the mesosphere. These processes trigger the chain of effects that propagate down in altitudes and moving from high to lower latitudes. In the paper we consider the possible relation of the SSW event in winter 2018 with cold weather anomaly in the Northern Ukraine and North-East China regions in February 2018.

\section{METHODOLOGY}

\subsection{DATA}

The data of air temperature, zonal wind, and geopotential height were used from the NCEPNCAR reanalysis data ([6], https://www.esrl.noaa.gov/psd/cgi-bin/data/). The NCEP-NCAR reanalysis data on time-latitude air temperature anomaly sequence allow to retrieve the delayed response of the near-surface temperature to the stratospheric anomalies in February-March 2018 (Fig. 1). The warm stratospheric anomaly at 10-200 $\mathrm{hPa}$ expands to lower latitudes and cold anomaly to $-8^{\circ} \mathrm{C}$ appears at the surface at $45-70^{\circ} \mathrm{N}$ with about one week delay after the SSW beginning and it was observed from February 20 till March 5 (Fig. 1d). The air surface temperature negative anomaly was observed overall at the end of February and beginning of March 2018 in the North-East Ukraine including region around Kharkiv city, where the microwave radiometer site for detecting mesosphere parameters is located [5]. The air surface temperature negative anomaly was observed also over North-East China in the same time period.

The latitude-height and longitude-height sections of daily air temperature anomalies from the NCEP-NCAR reanalysis data (https://www.esrl.noaa.gov/psd/data/composites/d ay/) were used to analyze the possible downward influence of the SSW event (Fig. 2). The temperature anomalies have been averaged in segment $30-40^{\circ} \mathrm{E}$ centered at Kharkiv (Fig. $2 \mathrm{a}-2 \mathrm{e}$ ) 
and zone $45-60^{\circ} \mathrm{N}$ (Fig. $2 \mathrm{f}-2 \mathrm{j}$ ). Surface negative temperature anomalies are observed mainly in the zone $45-60^{\circ} \mathrm{N}$ in late February-March (Fig. 1d), therefore the vertical profiles along the eastern longitudes $0-180^{\circ} \mathrm{E}$ (Fig. 2, lower panel) are averaged for this zone.

\section{RESULTS}

3.1 Time-latitude air temperature anomaly The longest cold period in time-latitude plot of surface temperature anomaly is seen on February 20-28 (Fig. 1d).
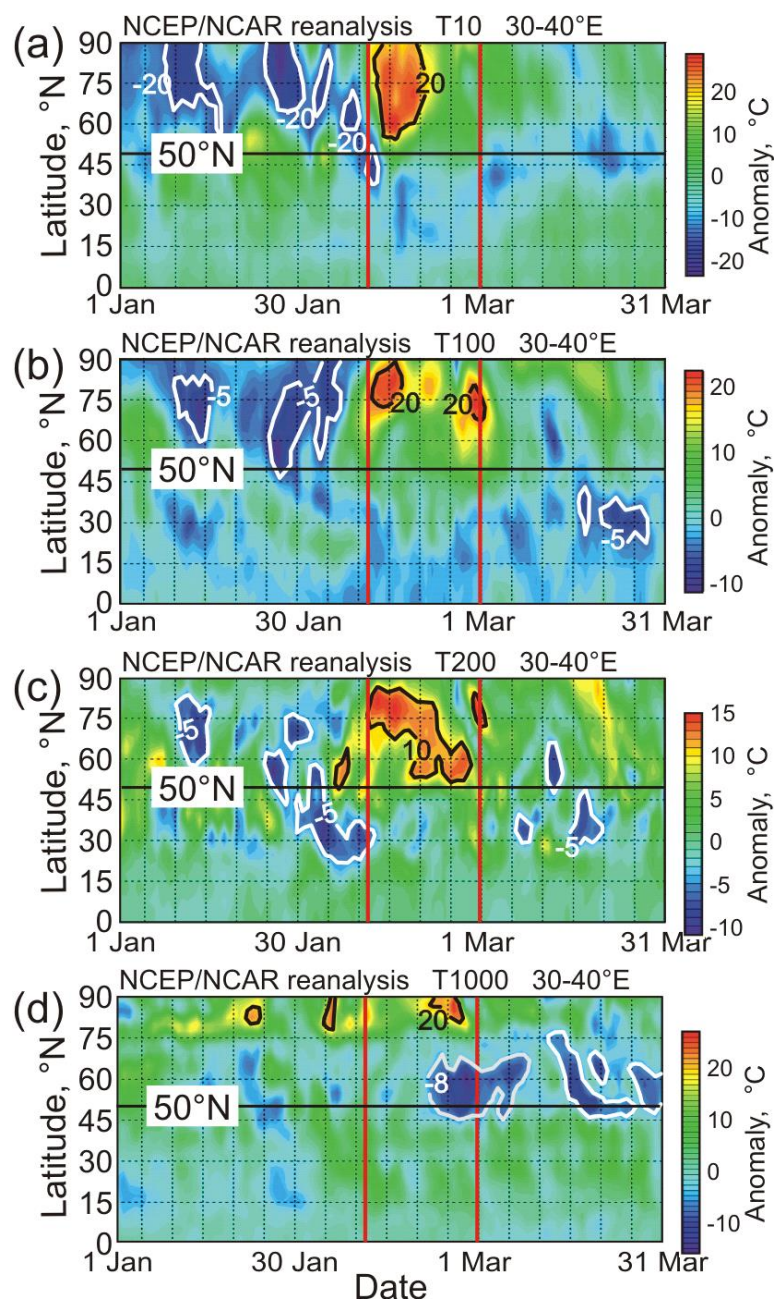

Figure 1. Time-latitude air temperature anomaly plots at the pressure levels 10, 100, 200 and 1000 $\mathrm{hPa}$ (T10, T100, T200 and T1000, respectively) during SSW event. Latitude $50^{\circ} \mathrm{N}$ is marked by black solid line. Climatology $1981-2010$ is used for the NCEP-NCAR reanalysis anomalies.

This cold temperature anomaly period is also confirmed by altitudinal distributions in Fig. 2.
Initially, the negative regional anomaly in the tropospheric temperature is formed at the north of the Kharkiv latitude $50^{\circ} \mathrm{N}$ (vertical line in Fig. 2). It locates in middle troposphere (white contours in Fig. $2 \mathrm{a}$ and $2 \mathrm{~b}$ ) and is vertically aligned with the southern edge of the strong positive stratospheric anomaly $\left(>10^{\circ} \mathrm{C}\right.$, thick black contour). The cold anomaly gradually descends between the tropopause (black dashed curve) and the surface, reaches the level $<-10^{\circ} \mathrm{C}$ and moves a little south of latitude $50^{\circ} \mathrm{N}$ synchronously with the positive stratospheric anomaly (Fig. 2a-2e). In zonal direction, both anomalies shift westward, however descent is observed only in the troposphere (Fig. $2 \mathrm{f}-2 \mathrm{j}$ ) similarly to the meridional section (upper panel in Fig. 2). The similar but weaker processes took place in the atmosphere at North-East China region in the longitudinal sector $110-130^{\circ} \mathrm{E}$ and averaged in latitudinal zone $45-60^{\circ} \mathrm{N}$ (see Fig. 2 f2j).

So, appearance of the cold surface anomaly in late February is associated with the strong warm anomaly in the stratosphere, which meridionally extends between the middle and polar latitudes and zonally covers the eastern longitudes (upper and lower panels, respectively, in Fig. 2). The downward stratosphere-troposphere coupling involves vertical dipole-like structure of the temperature anomalies appeared near 20 February, with a 10-day time delay relative to the starting date of the SSW (10 February).

It should be noted that the cold anomaly intensity is sensitive to the thermal tropopause, which declines in the North-East Ukraine (near Kharkiv) region to $400 \mathrm{hPa}(\sim 7 \mathrm{~km})$ on 24 and 26 February (black dashed curve in Fig. $2 \mathrm{c}, 2 \mathrm{~d}$ and $2 \mathrm{~h}$ ). The similar smaller tropopause altitude decline over the cold temperature anomaly is seen at the 110 $130^{\circ} \mathrm{E}$ latitudinal sector in the atmosphere at North-East China (see Fig. 2f-2j). This regional tropopause decline resembles the tropopause folding and suggests that the processes associated with stratosphere-troposphere exchange of air masses that can play a critical role in the cold weather formation [7]. Since the coldest air masses concentrated near the tropopause, their downward penetration could cause a cold anomaly occurrence in the troposphere. It should be noted that the warm tropospheric anomalies are 
sometimes observed under the elevated tropopause (Fig. 2b-2g).

\section{DISCUSSION}

As known, cold surface anomalies can be produced by downwelling of the stratospheric anomalies, they are associated with the negative phase of annular mode and the direct downward influence involves the whole polar region $[8,9$, 10]. The Arctic Oscillation (AO) index that describes annular mode phase had slightly positive value 0.1 in February 2018 (https://www.esrl.noaa.gov/psd/data/climateindice $\mathrm{s} /$ ). This does not suggest significant anomaly in zonal mean circulation and surface weather. The strongest surface anomaly up to $-10 \mathrm{~K}$ in late February covered mid- to high-latitude Europe between about $45^{\circ} \mathrm{N}$ and $70^{\circ} \mathrm{N}$ (Fig. $1 \mathrm{~d}$ and Fig. $2 \mathrm{c}-2 \mathrm{e}$ ) in the longitude sector $0-50^{\circ} \mathrm{E}$ (Fig. $2 \mathrm{~h}-$

$2 \mathrm{j}$ ). This shows that anomaly was relatively small zonally to be seen in global scale $\mathrm{AO}$ index.

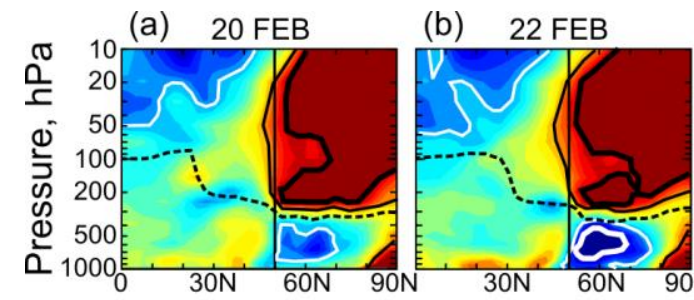

(c) $24 \mathrm{FEB}$

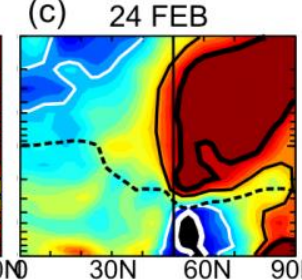

(d) 26 FEB

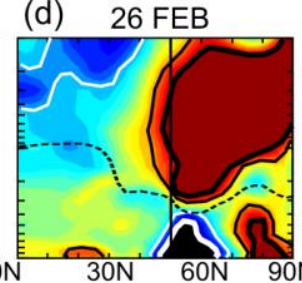

(e) 28 FEB

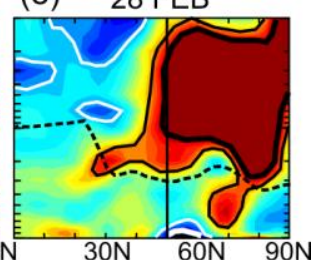

Latitude, degr.
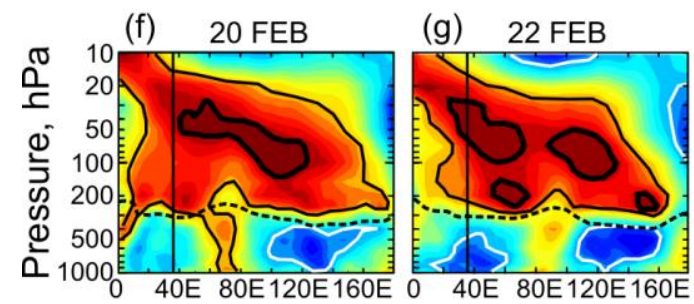

(h) 24 FEB
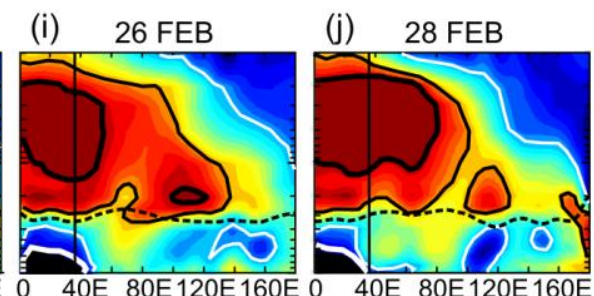

Longitude, degr.

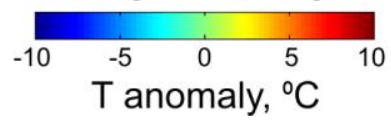

Figure 2. Daily vertical profiles of the air temperature anomalies in the troposphere-stratosphere in (a-e) latitude-height section, $0-90^{\circ} \mathrm{N}$, and (f-j) longitude-height section, $0-180^{\circ} \mathrm{E}$, averaged in segment 30 $40^{\circ} \mathrm{E}$ centred at longitude of Kharkiv and in zone $45-60^{\circ} \mathrm{N}$, respectively. Latitude and longitude of the Kharkiv site is marked by vertical line. Longitudinal sector of North-East China region is $110-130^{\circ} \mathrm{E}$ (not marked). Thin (thick) contours outline temperature anomalies of $\pm 5( \pm 10){ }^{\circ} \mathrm{C}$. Black dashed curve shows thermal tropopause pressure. From the NCEP-NCAR reanalysis data.

Cool surface anomaly in late February-early March 2018 lasted about two weeks (Fig. 1d) and it started 10 days after the SSW onset (10 and 20 February, respectively). This time delay is consistent with the time scale of stratospheric anomaly downwelling to the surface due to the SSW influences [8]. Downwelling of cold anomaly through the troposphere is also clearly observed and it occurs in coupling with warm anomaly in the lower stratosphere (Fig. 2). Therefore, generally, cold surface anomaly in Fig. $1 \mathrm{~d}$ and Fig. 2 could be interpreted as the regional midlatitude effect of the large-scale SSW event concentrated mainly in the polar region.

It is worthy of note that the surface cooling peak was reached 26 February (Fig. 2d and 2i) and it was preceded by a sharp weakening of upward wave flux. It may be suspected that wave reflection cold be involved in stratospheretroposphere coupling $[11,12]$ during this event. Whether or not the wave reflection took place in surface cooling in February 2018 should be additionally studied considering the longitudinal dependence of upward and downward wave 
propagation $[11,12]$ not represented in zonal means.

The stratosphere-troposphere coupling in late February 2018 was accompanied by significant decrease of the thermal tropopause height above the cold tropospheric anomaly in the North-East Ukraine including Kharkiv region (down to 400 $\mathrm{hPa}$, or $\sim 7 \mathrm{~km}$, on 24 and 26 February; black curve in Fig. 2c, 2d, $2 \mathrm{~h}$ and 2i). The similar but weaker processes took place in the atmosphere at North-East China region. It is possible that this tropopause anomaly evolves similarly to the tropopause folding with stratosphere-troposphere exchange of air masses, which can also contribute to the cold weather formation [7, 13]. These processes also need more detailed analysis.

\section{ACKNOWLEDGEMENTS}

This work was supported in part by Taras Shevchenko National University of Kyiv, project 19BF051-08; by the Institute of Radio Astronomy of the National Academy of Sciences of Ukraine; by the College of Physics, International Center of Future Science, Jilin University, China. NCEPNCAR reanalysis data were provided by the NOAA/OAR/ESRL PSD, Boulder, Colorado, USA, from their Web site at http://www.esrl.noaa.gov/psd/.

\section{REFERENCES}

[1] A. H. Butler, et al. Bull. Amer. Meteor. Soc., 96, 1913-1928, doi:10.1175/bams-d-13-00173.1 (2015)

[2] Y. Yu, et al. Mon. Weather Rev., 146, 2717-2739, doi:10.1175/MWR-D-18-0110.1 (2018)

[3] A. Chandran and R. L. Collins, Ann. Geophys., 32, 859-874, doi:10.5194/angeo-32-859-2014 (2014)

[4] Butler, A. H. et al., Earth Syst. Sci. Data, 9, 63-76, doi:10.5194/essd-9-63-2017 ( 2017)

[5] Y. Wang, et al. Atmos. Chem. Phys. Discuss. https://doi.org/10.5194/acp-2018-1361 (2019)

[6] E. Kalnay, et al. B. Am. Meteorol. Soc., 77, 10571072 (1996)

[7] B. Škerlak, et al. J. Geophys. Res. Atmos., 120, 4860-4877, doi:10.1002/2014JD022787 (2015)

[8] M. P. Baldwin and T. J. Dunkerton, Science, 294(5542), 581-584, doi:10.1126/science. 1063315 (2001)
[9] D. W. J. Thompson, et al. J. Clim., 15, 1421-1428 (2002)

[10] J. Kidston, et al. Nature Geoscience, 8, 433-440, doi:10.1038/ngeo2424 (2015)

[11] K. Kodera, et al. J. Geophys. Res. Atmos., 121, 80-94, doi:10.1002/2015JD023359 (2016)

[12] D. Nath, et al. Scientific Reports, 6, Article ID 24174, doi:10.1038 (2016)

[13] J. R. Holton, et al. Rev. Geophys., 33(4), 403-440, doi:10.1029/95RG02097 (1995) 